\title{
Lilin Aromaterapi dari Minyak Atsiri Kulit Jeruk Manis (Citrus sinensis)
}

\author{
Defe Lestari ${ }^{1, a}$, Eva Vidayanti ${ }^{1, b}$, Arif Jumari $^{1, *}$ \\ ${ }^{1}$ Teknik Kimia, Uniersitas Sebelas Maret dan Ir. Sutami Street No. 36 A Kentingan Surakarta 57126 \\ E-mail: ${ }^{a}$ defelestari08@gmail.com, beva.vidayanti98@gmail.com, \\ *Corresponding author: arifjumarift@staff.uns.ac.id
}

\begin{abstract}
Sweet orange peel is a waste. There is a high economic valued chemical compound of essential oil called limonene which has a distinctive fresh aroma.. Essential oil of Limonene was extracted from orange peel then was applied as aromatherapy candles. The essential oils was separated through liquid vapor distillation for 3 hours. The essential oil was then added to aromatherapy wax and stearic acid. The result showed that 200 grams of orange peel yielded 2,3 mL with weight 1.957 grams of essential oil. There was 2 (two) samples of aromatherapy candle that was made by adding essential oil, i.e., sample no. 1 with essential oil of $3 \mathrm{~mL}$ and $5 \mathrm{~mL}$ for sample 2.. The aromatherapy candles had tested for flame duration and product acceptance in the community. The result showed that the higher the content of Essential oil of Limonene the longer the flame duration and the higher the acceptance in the community. The essential oil of Limonene obtained from sweet orange peel was able to improve the quality of candles
\end{abstract}

Keyword : sweet orange peel, essential oil of Limonene, extraction, distillation, aromatherapy candle

EQUILIBRIUM Volume 3 No.2 December 2019

Online at http:/ / equilibrium.ft.uns.ac.id 


\section{Pendahuluan}

Buah Jeruk merupakan buah lokal yang sering ditemukan di Indonesia, khusunya kota Surakarta. Buah jeruk sendiri dapat diolah menjadi berbagai jenis olahan yang sangat bermanfaat. Jeruk manis (Citrus sinensis) salah satu jenis jeruk yang dikonsumsi dengan cara diperas untuk dijadikan minuman. Selama ini kulit jeruk manis (Citrus sinensis) belum sepenuhnya termanfaatkan dan menjadi limbah yang dibuang begitu saja. Sementara kulit dari buah jeruk memiliki kandungan yang bermanfaat, sehingga kulit buah jeruk dapat diolah menjadi produk yang berguna bagi masyarakat [1].

Kulit buah jeruk manis basah akan lebih baik digunakan dibandingkan dengan kulit buah jeruk manis yang sudah dikeringkan. Hal ini dikarenakan dalam kulit buah jeruk manis basah mengadung minyak atsiri yang ada belum seluruhnya menguap sehingga langsung dapat diambil minyaknya. Selain itu, aroma yang diperoleh dari minyak atsirinya masih segar dengan baun khas buah jeruk.

Dalam kulit jeruk manis terdapat senyawa kimia yang dapat dimanfaatkan karena memiliki gugus penyusun pektin dan minyak atsiri. Komponen minyak atsiri dari kulit jeruk manis terdiri dari limonene (95\%), mirsen $(2 \%)$, oktanal $(1 \%)$, dekanal $(0,4 \%)$, sitronelal $(0,1 \%)$, neral $(0,1 \%)$, geranial $(0,1 \%)$, valensen $(0,05 \%)$, sinnsial $(0,02 \%)$, dan sinensial $(0,01 \%)$ [2]. Senyawa limonene yang terdapat di dalam kulit jeruk inilah yang membuat minyak atsiri kulit jeruk mahal karena beraroma yang khas [3,4]. Oleh karena itu, kulit jeruk akan sangat bermanfaat jika diekstrak untuk mendapatkan minyak atsirinya. Pemamfaatan minyak atsiri dari kulit jeruk

Minyak atsiri kulit jeruk sering disebut minyak eteris (aetheric oil). Minyak atsiri jeruk dapat digunakan sebagai pengharum ruangan, bahan parfum, dan penambah cita rasa pada makanan [5]. Minyak atsiri jeruk juga bermanfaat bagi kesehatan, yaitu untuk aromaterapi. Aroma jeruk dapat menstabilkan sistem syaraf dan menimbulkan perasaan senang. Karena kandungan minyak atsiri kulit jeruk menimbulkan aroma yang dapat menstabilkan sistem syaraf sehingga dapat dibuat produk aromaterapi. Ada berbagai macam bentuk aromaterapi yaitu, minyak essensial aromaterapi, dupa aromaterapi, lilin aromaterapi, minyak pijat aromaterapi, garam aromaterapi, dan sabun aromaterapi. Karena maanfaat minyak atsiri dari kulit jeruk yang baik untuk kesehatan, sehingga perlu diteliti bagaimana pemanfaatannya. Dalam penelitian ini minyak atsiri dari kulit jeruk dipisahkan/diambil dengan destilasi. Minyak atsiri yang diperoleh selanjutnya dimanfaatkan sebagai aromaterapis dalam bentuk sebagai lilin aromaterapi.

Teknik yang dapat digunakan untuk memperoleh minyak atsiri ada beberapa proses, yaitu dengan proses: ekstraksi, pengepresan, penyulingan, dan maserasi $[6,7]$. Proses ekstraksi adalah melarutkan minyak atsiri dalam bahan dengan menggunakan pelarut organik yang bersifat mudah menguap. Ekstraksi menggunakan pelarut organik biasanya digunakan untuk mengekstraksi minyak atsiri yang mudah rusak karena pemanasan dengan uap dan air [8]. Pelarut yang digunakan dalam proses ekstraksi yaitu: alkohol, petroleum eter, dan benzene [6]. Pengambilan minyak atsiri secara mekanis dilakukan dengan metode pengepresan. Cara ini hanya dilakukan apabila kandungan minyak atsiri dalam bahan cukup banyak yaitu berkisar 30-70\%, sehingga dapat dilihat tetes-tetes minyaknya dengan mata telanjang atau dapat ditekan dengan tangan. Penyulingan (distilasi) untuk mendapatkan minyak atsiri yaitu hydro distillation dan steam distillation. Rendemen yang didapat dengan metode distilasi uap cair adalah $0,1 \%$ [9]. Rendemen yang didapat dengan proses bydro distillation sekitar 0,35\%-0,37\% [10]. Proses distilasi dilakukan terdiri dari dua tahap yaitu perlakuan pendahuluan dan pemisahan minyak kulit jeruk. Maserasi adalah proses ekstraksi dengan cara perendaman sampel pelarut organik pada suhu ruangan. Proses ini sangat berguna untuk isolasi senyawa bahan alam karena melalui perendaman sampel tumbuhan akan terjadi pemecahan dinding sel dan membran sel yang disebabkan oleh perbedaan tekanan di daerah luar dan dalam sel sehingga metabolit sekunder yang ada pada sitoplasma akan terlarut dalam pelarut organik dan ekstraksi senyawa akan sempurna karena dapat diatur lama perendaman yang akan dilakukan. Penelitian ini menggunakan metode distilasi uap cair karena memiliki memiliki rendemen yang tinggi untuk bahan kulit jeruk.

Penelitian ini bertujuan untuk memisahkan minyak atsiri limbah kulit jeruk manis dan memanfaatkannya dalam bentuk lilin aromaterapi.

\section{Metodologi}

\subsection{Bahan}

Penelitian ini menggunakan bahan-bahan yang meliputi : kulit jeruk manis, aquades, Asam stearate (teknis), paraffin (teknis), tartazine (teknis) 


\subsection{Pelaksanaan penelitian}

Proses penyulingan minyak atsiri kulit jeruk manis (Citrus sinensis) yaitu dimulai dari pembersihan daging buahnya. Kemudian kulit jeruk dilakukan pengecilan ukuran. Kulit jeruk didistilasi dengan pelarut air menggunaan alat distilasi uap-cair untuk didapatkan minyak atsiri. Kulit jeruk manis sebanyak 200 gram dilakukan distilasi selama 3 jam. Berdasarkan hasil distilasi didapatkan campuran antara minyak dan air kemudian dipisahkan menggunakan alat dekanter untuk diambil minyak atsiri kulit jeruk manis. Minyak atsiri pada bagian atas dan air pada bagian bawah. Selanjutnya proses pembuatan lilin dengan bahan dasar parafin dan asam stearat sebanyak 75 gram dan 25 gram (3:1) dipanaskan hingga larut [11]. Larutan lilin diukur dengan volume $40 \mathrm{~mL}$, kemudian ditambahkan $3 \mathrm{~mL}$ minyak atsiri untuk sampel 1 dan $5 \mathrm{~mL}$ minyak atsiri untuk sampel 2 serta ditambahkan pewarna sebanyak 0,1 gram pewarna tartazine [12]. Setelah kering, lilin aromaterapi dikemas dan diberi label kemasan. Kemudian dilakukan pengujian yaitu tahan lama lilin aromaterapi dibakar dan penerimaan produk oleh calon konsumen dengan uji organoleptik (pengujian menggunakan alat indra)

\section{Hasil dan Pembahasan}

Hasil Penyulingan Minyak Atsiri Kulit Jeruk Manis (Citrus sinensis) diperoleh dari distilasi pada penelitian ini didapatkan volume minyak atsiri terbanyak $2,3 \mathrm{~mL}$ dengan berat sebesar 1,957 gram. Rendemen yang didapatkan sebesar $0,97 \%$ dan densitas $0,771 \mathrm{gram} / \mathrm{mL}$. Namun, rata-rata minyak atsiri yang diperoleh sekitar 1,5-2,3 mL setiap satu kali distilasi. Perbedaan hasil minyak atsiri pada penelitian ini dengan penelitian Alfian Nur (2017) dikarenakan preparasi bahan yang berbeda. Pada penelitian Alfian Nur (2017) kulit jeruk manis (Citrus sinensis) dipotong $2 \mathrm{~cm}$ kemudian dimasukkan kedalam alat distilasi, sedangkan pada penelitian ini juga dilakukan pengecilan bahan kulit jeruk manis menggunakan food. Pengecilan kulit jeruk membuat ukuran kontak bahan menjadi lebih besar sehingga hasil yang diperoleh lebih banyak.

Pembuatan Lilin Aromaterapi dari Minyak Atsiri Kulit Jeruk Manis (Citrus sinensis) terdapat 2 sampel yaitu lilin dengan tambahan minyak atsiri $3 \mathrm{~mL}$ untuk sampel 1 dan $5 \mathrm{~mL}$ sampel 2. Bahan utama pembuatan lilin berupa 75 gram parafin dan 25 gram asam stearat dengan perbandingan (3:1). Kemudian ditambah 0,1 gram pewarna tartazine dan dicetak dengan gelas kecil. Penggunaan gelas ini dikarenakan agar nyala lilin tahan lama. Hasil pengujian Lilin Aromaterapi dari Minyak Atsiri Kulit Jeruk Manis (Citrus sinensis) dilakukan dengan 2 variasi perbandingan volume minyak atsiri ditampilkan pada tabel $1 .$.

Tabel 1. Bentuk dan warna serta hasil pengujian durasi pembakaran lilin aromaterapi

\begin{tabular}{cccccc}
\hline Sampel & Formula & Bentuk & Warna & $\begin{array}{c}\text { Durasi } \\
\text { pembakaran }\end{array}$ & $\begin{array}{c}\text { Kondisi } \\
\text { aroma }\end{array}$ \\
\hline 1 & $\begin{array}{c}\text { Parafin }+ \text { Asam Stearat } \\
+ \text { Pewarna }+ \\
\text { Minyak Atsiri kulit jeruk } \\
\text { manis } 3 \mathrm{~mL}\end{array}$ & Orange & Padat & 5 jam 20 menit & Kuat \\
& & & & \\
2 & $\begin{array}{c}\text { Parafin }+ \text { Asam Stearat } \\
+ \text { Pewarna }+\end{array}$ & Orange & Padat & 5 jam 55 menit & Lebih Kuat \\
& $\begin{array}{c}\text { Minyak Atsiri kulit jeruk } \\
\text { manis } 5 \mathrm{~mL}\end{array}$ & & & & \\
& & & & \\
\hline
\end{tabular}

Pembuatan lilin aromaterapi dengan tambahan minyak atsiri $5 \mathrm{~mL}$ memiliki aroma lebih menyengat dibanding lilin aromaterapi dengan penambahan minyak atsiri $3 \mathrm{~mL}$. Berdasarkan pengujian yang telah dilakukan dengan menyalakan lilin sampai habis didapatkan lilin aromaterapi yang tahan lama yaitu pada sampel 2 lilin dapat menyala selama 5 jam 55 menit dibandingkan dengan 5 jam 20 menit pada lilin aroma terapi dengan kandungan minyak atsiri $3 \mathrm{ml}$. Hal ini karena minyak atsiri yang lebih tidak mudah terbakar dibandingkan paraffin pad lilin sehingga menghambat pembakaran paraffin. Selain itu pengujian juga memberikan hasil bahwa aroma yang lebih kuat terjadi pada pembakaran lilin dengan kandungan minyak atsiri yang lebih banyak. Hal ini karena gas yang dihasilkan dari pembakaran lilin mengandung lebih banyak minyak atsiri limonene sehingga aromanya lebih kuat. 
Hasil pengujian lilin arome terapi secara organoleptik (pengujian menggunakan alat indra) juga dilakukan pada masyarakat (calon pengguna lilin aroma terapi) dan hasilnya ditampilkan pada gambar 1 dan gambar 2.

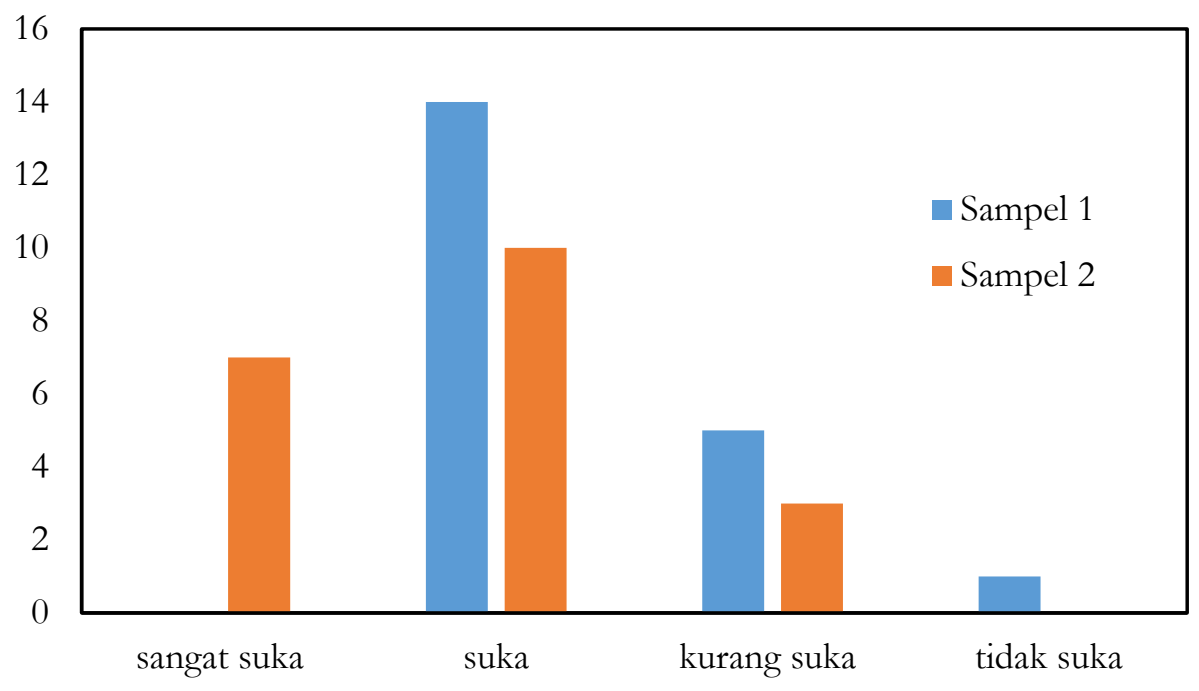

Gambar 1. Hasil pengujian organoleptic dengan parameter aroma lilin

Pada pengujian yang dilakukan terhadap 20 responden dengan pertanyaan sangat suka, suka, kurang suka, dan tidak suka. Hasil yang diperoleh yaitu pada sampel 2 memiliki nilai paling banyak sangat suka dan suka yang lebih tinggi dibandingkan sampel 1. Hal ini dikarenakan pada sampel 2 volume minyak yang ditambahkan sebanyak $5 \mathrm{~mL}$ sehingga aroma yang ditimbulkan lebih berasa dan tercium daripada sampel 1 . Aroma pada sampel 2 ini cocok untuk responden yang sangat menyukai aroma jeruk yang menyengat.. Hasil pengujian yang telah dilakukan adalah sampel 1 memiliki bau khas aromatik yang lemah dan bau khas aromatik kuat dari sampel 2.

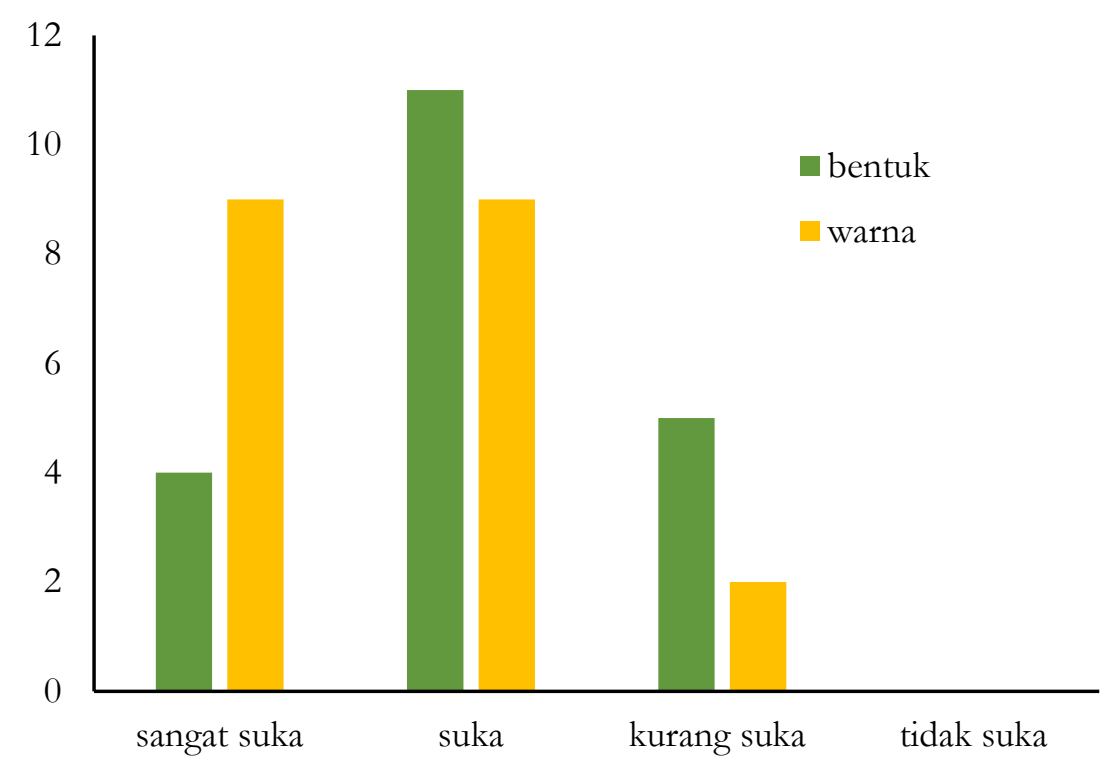

Gambar 2 . Hasil pengujian organoleptic dengan parameter bentuk dan warna Lilin

Pengujian dengan parameter bentuk dan warna lilin dilakukan terhadap 20 responden dengan pertanyaan sangat suka, suka, kurang suka, dan tidak suka. Pada parameter uji bentuk responden menyukai bentuk lilin aromaterapi yang diberi tempat berupa gelas kaca kecil yang membuat lilin aromaterapi dapat bertahan lama. Pada parameter uji warna, responden sangat menyukai lilin aromaterapi yang ditambahi warna orange. Lilin 
aromaterapi akan lebih menarik dan juga identik dengan buah jeruk.

\section{Kesimpulan}

Minyak atsiri kulit jeruk yaitu lemonen diekstrak melelui distilasi uap-cair dengan hasil 2,3 mL dengan berat sebesar 1,957 gram dari setiap 200 gram kulit jeruk. Penambahan $5 \mathrm{ml}$ minyak atsiri pada 100 gram lilin aromaterapi memberikan aroma yang lebih baik dan durasi penggunaan yang lebih lama ( 5 jam 55 menit) dibandingkan penambahan $3 \mathrm{ml}$ denag durasi penggunaan 5 jam 20 menit. Lilin aroma terapi dengan minyak atsiri yang lebih besar juga lebih disukai responden.

\section{Daftar Pustaka}

[1]. Kartasapoetra. 2001. "Budidaya Tanaman Berkhasiat Obat”. Jakarta : PT. Rineka Cipta.

[2]. Megawati, Rosa Dwi Kurniawan, 2015, Ekstraksi Minyak Atsiri Kulit Jeruk Manis (Citrus Sinensis) Dengan MetodeVacuum Microwave Asissted Hydrodistillation, Jurnal Bahan Alam Terbarukan, JBAT 4 (2) (2015) 61-67

[3]. Primadiati, Rachmi. 2002. "Aromaterapi: Perawatan alami untuk sehat dan cantik". Jakarta : PT Gramedia Pustaka Utama.

[4] Buchbauer, G., W. Jager, H. Dietrich, Ch. Plank, and E. Karamat. 1991. "Aromatherapy: Evidence for sedative Effects of Essential Oil of Lavender after Inhalation”. Journal of Biosciences. 46c,1067-1072

[5]. Badan Penelitian dan Pengembangan Pertanian. 2008. "Menghasilkan Minyak Daun Cengkeh Bermutu. Warta Penelitian dan Pengembangan Pertanian 30:(5). Hal 5-7.

[6] Guenther, E. 1987. "Minyak Atsiri Jilid I (Terjemahan). Jakarta : Penerbit UI-Press.

[7] Adityo, Kurniawan, dkk. 2008.”Ekstraksi Minyak Kulit Jeruk dengan Metode Distilasi, Pengepresan, dan Leaching". Widya Teknik. Vol. 7 No. 1. Surabaya: Universitas Katolik Widya Mandala.

[8] Danarto, YC dan Mujtahid Kaavessina. 2014.’Petunjuk Praktikum Satuan Operasi II”. Surakarta: Universitas Sebelas

[9 ]Alfianur. 2017. "Identifikasi Komponen Penyusun Minyak Atsiri Kulit Jeruk Manis (Citrus sinensis L.) Asal Selorejo dan Uji Aktivasi Antibakteri Menggunkan Metode Kertas Cakram". Undergraduated Thesis. Universitas Islam Negeri Maulana Malik Ibrahim.

[10] Ramadhani, E. D. dan Rikko Bimantara. 2011. "Efisiensi Waktu Operasi Terhadap Hasil Rendemen pada Pengambilan Minyak Atsiri dari Kulit Jeruk dengan Menggunakan Metode Distilasi”. Tugas Akhir Juruan Teknik Kimia, Institut Teknologi Sepuluh November.

[11] Nilna, Minah F, dkk. 2017.’Pembuatan Lilin Aroma Terapi Berbasis Bahan Alami”. Industri Inovatif. Vol. 7 No 1. Malang: Institut Teknologi Nasional.

[12] Hussein, M. Saddam, dkk. 2016. "Rancang Bangun Pengendalian Pembuatan Lilin Aromaterapi Berbasis Programmable Logic Controller". Jurnal Utek (ISSN: 1693-8097). Vol. 12 No. 1. Hal 25-29 